\title{
How to understand diversity in citizens' care attitudes: an exploratory study in the Netherlands
}

\author{
Yvette Wittenberg ${ }^{1,2 \star}$ (D), Alice H. de Boer ${ }^{3,4}$, Mirjam M. Y. de Klerk ${ }^{4}$, Arnoud P. Verhoeff ${ }^{1,5}$ \\ and Rick Kwekkeboom ${ }^{2}$ \\ ${ }^{1}$ Faculty of Social and Behavioural Sciences, University of Amsterdam, Amsterdam, The Netherlands, \\ ${ }^{2}$ Faculty of Applied Social Sciences and Law, Amsterdam University of Applied Sciences, Amsterdam, \\ The Netherlands, ${ }^{3}$ Faculty of Social Sciences, VU Amsterdam, Amsterdam, The Netherlands, \\ ${ }^{4}$ The Netherlands Institute for Social Research, The Hague, The Netherlands and ${ }^{5}$ Public Health Service \\ Amsterdam, Amsterdam, The Netherlands \\ ${ }^{*}$ Corresponding author. Email: y.wittenberg@hva.nl
}

(Accepted 22 June 2021; first published online 2 August 2021)

\begin{abstract}
The aim of this study is to investigate Dutch citizens' care attitudes by looking at care-giving norms and citizens' welfare state orientation and to explore to what extent these attitudes can be explained by combinations of diversity characteristics. We combined two datasets (2016 and 2018, $\mathrm{N}=5,293$ ) containing citizens' opinions regarding society and conducted multivariate linear and ordered probit regression analyses. An intersectional perspective was adopted to explore the influence of combinations of diversity characteristics. Results show that citizens' care-giving norms are relatively strong, meaning they believe persons in need of care should receive help from their families or social networks. However, citizens consider the government responsible for care as well. Men, younger people, people in good health and people of non-Western origin have stronger care-giving norms than others, and younger people assign relatively more responsibility to the family than the government. Level of education and religiosity are also associated with care attitudes. Primary diversity dimensions are more related to care attitudes than secondary, circumstantial dimensions. Some of the secondary dimensions interact with primary dimensions. These insights offer policy makers, social workers and (allied) health professionals the opportunity to align with citizens' care attitudes, as results show that people vary to a large extent in their care-giving norms and welfare state orientation.
\end{abstract}

Keywords: informal care; care attitudes; care-giving norms; welfare state orientation; intersectionality; regression analysis; social work; health occupations

\section{Background}

The populations' ageing and changes in family and working life call for changes in organising care (Daatland and Herlofson, 2003; Haberkern and Szydlik, 2010). In

\footnotetext{
(C) The Author(s), 2021. Published by Cambridge University Press. This is an Open Access article, distributed under the terms of the Creative Commons Attribution-NonCommercial-NoDerivatives licence (http://creativecommons.org/licenses/ by-nc-nd/4.0/), which permits non-commercial re-use, distribution, and reproduction in any medium, provided the original work is unaltered and is properly cited. The written permission of Cambridge University Press must be obtained for commercial re-use or in order to create a derivative work.
} 
recent years, the accessibility of publicly funded services has decreased and social networks' care responsibility has become more emphasised (Triantafillou et al., 2010; Broese van Groenou and de Boer, 2016; van den Broek et al., 2019). These policy shifts suggest that reducing care provisions will be compensated by increased informal care and that the message thus given will be incorporated in general care attitudes. However, it is not clear whether this assumption is realistic (Verbakel, 2017a). Recent Dutch studies do not give a clear answer to the question whether care attitudes are shifting towards the direction desired. Although public opinion seems to shift towards more family responsibility, most Dutch citizens still think elderly care is mainly the government's responsibility (Verbakel, 2014; de Klerk et al., 2017). More recent insights into care attitudes are needed to get a better understanding of Dutch citizens' preferences regarding the division of care responsibilities.

Scientific research has devoted increasing attention to care-givers' profiles and trends in informal care provision (Triantafillou et al., 2010; Verbakel, 2017a, 2017b), but not to understanding care attitudes (Dykstra and Fokkema, 2012; van den Broek et al., 2015). Understanding differences in care attitudes enables professionals to align better with people's preferences and helps policy makers to understand how formal services could be (re)arranged to meet a wide variety of expectations (Daatland and Herlofson, 2003; Dykstra and Fokkema, 2012; van den Broek et al., 2015). The Netherlands provides an interesting context, because of its generous welfare state arrangements (van den Broek et al., 2019) and individualistic cultural norms (Dykstra and Fokkema, 2012). Changes in Dutch long-term care policies are exemplary to other European countries which are trying to shift care responsibilities towards the family or social networks as well (Verbeek-Oudijk et al., 2014). We will therefore explore recently expressed care attitudes of Dutch citizens of various backgrounds.

\section{Diversity in care attitudes}

Care attitudes are defined as citizens' opinions regarding the division of care responsibilities between family and/or social networks and the welfare state. Several studies discern specific aspects of such normative care beliefs, such as filial norms or responsibility, on the one hand, and the extent to which individuals consider the state responsible for organising care, on the other (Daatland and Herlofson, 2003; van den Broek et al., 2015). In this study, we will focus on both care-giving norms and welfare state orientation to investigate care attitudes. Because we focus on care responsibilities in families and/or social networks, we broaden the often-used definition of filial norms (Lee et al., 1998; Daatland and Herlofson, 2003; Gans and Silverstein, 2006). Care-giving norms refer to the recognised duties and obligations that define all citizens' social role with respect to close ones who need care (Gans and Silverstein, 2006). Welfare state orientation reflects expectations concerning the relative responsibilities of the social network and the welfare state (Daatland and Herlofson, 2003). Some authors find an association between those aspects: citizens with strong filial norms contribute less care responsibility to the state and thus emphasise the networks' responsibility (Daatland and Herlofson, 2003; Verbakel, 2014). However, there are also indications that strong filial norms can go along with a strong preference for the state providing care (Dykstra and Fokkema, 2009). Because there seems to be no unequivocal answer 
to how both aspects of care attitudes are associated, we will look into both aspects and its determinants separately, to grasp care attitudes of citizens fully (van den Broek et al., 2015).

To be able to understand differences in care attitudes, we use intersectionality. The concept of intersectionality, coined by Crenshaw at the end of the 1980s (Davis, 2008; Bauer, 2014), offers the opportunity to gain critical insights of how care-giving issues are framed and formed by diversity (Williams et al., 2016). 'Intersectionality' refers to the interaction between dimensions of difference in individual lives, social practices, institutional arrangements and cultural ideologies, and the consequences of these interactions where distribution of power is concerned (Davis, 2008; Hankivsky, 2014). Within this reasoning care can be seen and experienced as an inequalitycreating phenomenon as a result of institutionalised patterns of cultural norms and values (Akkan, 2020). Young women, for instance, may face inequalities because of care-giving expectations that hinder them to pursue other ambitions in their lives. Akkan (2020) argues that such feminist thinking around care issues takes its strength from the contextuality approach, that states that the morality and the practice of care are intertwined. Hancock (2007) defines intersectionality as a body of normative theory and empirical research that proceeds under six key assumptions: (a) more than one category of difference plays a role, (b) these categories should be equally attended to and the relationship between them is an open empirical question, (c) categories are conceptualised as dynamic productions of individual and institutional factors, (d) each category has within-group diversity, (e) categories should be examined at multiple levels, and (f) attention to both empirical and theoretical aspects of the research question is needed (Hancock, 2007). Other scholars present dimensions of inequality as closely intertwined and argue as well that these forms of stratification need to be studied in relation to each other (Choo and Ferree, 2010; Winker and Degele, 2011; Hankivsky, 2014). In care-giving research, the intersectionality approach is nowadays seen as an important tool to articulate the multi-dimensional and relational nature of care-giving and the social conditions under which care is provided (Chappell et al., 2015; Dilworth-Anderson et al., 2020). However, little is known about intersectionality in care attitudes.

Whilst investigating care attitudes, researchers have found relationships with several diversity characteristics, such as cultural backgrounds and socio-cultural circumstances (Daatland and Herlofson, 2003; Gans and Silverstein, 2006; Beneken genaamd Kolmer et al., 2008; Dykstra and Fokkema, 2012; Verbakel, 2014; van den Broek et al., 2015; Santoro et al., 2016). These examples underline the importance of investigating not only personal dimensions of diversity, but also situational circumstances. The intersectional approach allows us to do so, as it conceptually focuses on both personal and situational dimensions of diversity, assuming associations between citizens' social identities and situational circumstances. Thus, this approach can provide insight into the mutual reinforcement of these characteristics in relation to care attitudes (Hancock, 2007; Hankivsky and Cormier, 2009; Rouhani, 2014). Not only focusing on single dimensions of diversity but investigating interactions among these dimensions as well could better reflect the complexity of shaping care attitudes (Giesbrecht et al., 2012; Hunting, 2014).

Following the intersectional approach, we consider the relationships among diversity characteristics as an open empirical question (Hancock, 2007; 
Hankivsky and Cormier, 2009), which means that no dimensions of diversity will be given favour in our analysis (McCall, 2005; Giesbrecht et al., 2012). However, we did decide to use a pragmatic classification of dimensions of diversity in order to increase the readability of this study. When we write about 'primary dimensions of diversity' we mean personal diversity characteristics considering social identities, and writing about 'secondary dimensions of diversity' we mean situational circumstances (Loden and Rosener, 1990; Hankivsky and Cormier, 2009).

\section{Diversity characteristics and hypotheses}

\section{Primary dimensions}

Previous studies are ambiguous about the association between gender and filial norms. In some studies women are assumed to have stronger filial norms than men, making caring a gendered concept (Daatland and Herlofson, 2003; Dykstra and Fokkema, 2012). According to van den Broek et al. (2015), however, European studies reveal men having stronger filial norms than women. Dutch studies on welfare state orientation have established that women more often consider the government responsible for care (van den Broek et al., 2015; Hoefman et al., 2017). Younger people have stronger filial norms (Gans and Silverstein, 2006; Dykstra and Fokkema, 2012), but at the same time they assign the care responsibility to the government more often than elderly people (Hoefman et al., 2017). A relationship between (self-reported) health status and care attitudes was found in one study, revealing that a worse health status leads to considering the state responsible for care (Verbakel, 2014). Various researchers (Lee et al., 1998; Blieszner and Bedford, 2012) have found ethnic differences: people sharing collectivistic values, such as many from non-Western cultures, perceive care as a family responsibility, while care-givers from individualistic cultures rely on external services (Santoro et al., 2016). Dykstra and Fokkema (2012) state that migrants living in the Netherlands have stronger filial norms than people of Dutch origin.

From the literature on primary dimensions it can be concluded that care-giving norms and welfare state orientation have partly different determinants. Therefore, our first hypothesis (Hypothesis 1) is formulated as follows: where strong caregiving norms are assumed to be overrepresented in men, younger persons, those in good health and those of non-Western origin, a stronger government orientation can be expected to be seen within women, younger persons, those with health problems and those of Dutch or other Western origin.

\section{Secondary dimensions}

Studies show higher-educated people having a more individualistic lifestyle and weaker care-giving norms (Gans and Silverstein, 2006; Dykstra and Fokkema, 2012; van den Broek et al., 2015). Higher-educated people place less responsibility on the government (Verbakel, 2014; Hoefman et al., 2017). Employed or financially advantaged families show a lesser sense of obligation to provide care themselves (Gans and Silverstein, 2006; van den Broek et al., 2015). People with a job have less spare time to provide care, so it is expected that they adjust their care-giving norms downwards (Dykstra and Fokkema, 2012). Hoefman et al. (2017) found an association between working part-time and assigning the government more 
care responsibility. People with children prove to attribute families fewer caring responsibilities, because parents may not want to burden their children (Dykstra and Fokkema, 2012; van den Broek et al., 2015). Religious people have stronger filial norms than others (Dykstra and Fokkema, 2012; Mair et al., 2015) and feel a stronger family care responsibility (Daatland and Herlofson, 2003; Verbakel, 2014). Care attitudes may predict the tendency of people to provide informal care (Silverstein et al., 1995, 2006; Dykstra and Fokkema, 2012), but the decision to actually provide informal care is also influenced by other circumstances such as the need for care, perceived barriers and social context (Broese van Groenou and de Boer, 2016). Being a care-giver may lead to endorsing strong care-giving norms (Silverstein et al., 1995, 2006; Dykstra and Fokkema, 2012) as well as to asking the government to shoulder care responsibility (Hoefman et al., 2017).

Many studies provided evidence on secondary dimensions of care attitudes. Based on these insights, we hypothesise (Hypothesis 2) that, on the one hand, people with lower education and those who are unemployed or financially disadvantaged, without children, religious and care-givers will have stronger care-giving norms. On the other hand, people who have higher education and those who are employed or financially advantaged, have children, are not religious and are not care-givers will consider the government responsible for care.

In addition to these hypotheses regarding diversity's direct influences on care attitudes, we investigate indirect influences as well. As mentioned before, in intersectional research, the relationships among diversity characteristics are viewed as an open empirical question in which an integrative analysis of the interaction between citizens' social identities and situational circumstances is seen as a relevant approach (Hancock, 2007; Hankivsky and Cormier, 2009). We thus hypothesise (Hypothesis 3 ) that there are interactions of primary and secondary diversity characteristics in our models. Specific literature on such interactions whilst investigating care attitudes is lacking. However, based on more general care-giving literature it is known that, for example, gender intersects with other axes of difference, such as culture, socio-economic status, marital status and geography (Giesbrecht et al., 2012; Browning, 2021), and that age is associated with other differences such as socio-economic status, employment status, marital status and being a care-giver or not (Kenny et al., 2014; Browning, 2021). Compared to other studies on care attitudes in which these interactions are not considered, these insights potentially better reflect the complexity of shaping care attitudes, as the focus is based not only on differences on single dimensions of diversity (Giesbrecht et al., 2012; Hunting, 2014).

\section{Methods}

\section{Sample}

We use two datasets of the Netherlands Institute for Social Research which contained citizens' opinions about society. These datasets are based on surveys conducted in 2016 and 2018. The first quantitative study (2016) was carried out among a representative sample of the Dutch population aged 16 and older. Citizens within this sample $(\mathrm{N}=5,387)$ received a letter about the study in which the visit of an interviewer at 
home was announced. Trained interviewers executed the interviews at home using a digital questionnaire. Out of this sample eventually 2,690 respondents participated in the study (Coumans and Knops, 2017). The second quantitative study was conducted the same way in 2018. Out of the total representative sample $(\mathrm{N}=4,570)$ eventually 2,609 respondents participated (Coumans and Knops, 2019). For the study described in this paper, we combined the datasets of 2016 and 2018 to get a robust dataset of 5,293 respondents aged 16 and over.

\section{Measurements}

Care-giving norms are measured by three items combined into a 1-5 scale (Cronbach's $\alpha=0.62$ ). The scale reflects to what degree citizens think that (a) people with long-term illness or limitations should receive help as much as possible from family, friends or neighbours; (b) adult children are obliged to provide care to their parents when in need; and (c) it is good that the government expects citizens to provide care to each other in case of chronic illness or disability. A score of 1 reflects the weakest care-giving norm and a score of 5 the strongest, meaning that persons are more likely to think persons in need of care should receive help from their families and/or social networks.

Welfare state orientation is often measured on a scale ranging from 'completely a state responsibility' to 'completely a family responsibility' (Daatland and Herlofson, 2003; Haberkern and Szydlik, 2010; Verbakel, 2014; van den Broek et al., 2015). To gauge this, respondents were asked whether they think elderly care is mainly the government's responsibility or mainly the family's. Possible answers were (a) mainly a government task, (b) more a government task than a family task, (c) more a family task than a government task or (d) mainly a family task. As in the care-giving norm scale, the highest value reflects a care attitude holding the family most responsible.

As independent variables we used all available diversity characteristics in the dataset that could be associated with care attitudes. We included gender (male or female), age (16-34, 35-64 or 65+ years old), self-reported health status (not limited or limited) and origin (Dutch/other Western or non-Western) as primary dimensions of diversity. Additionally, we included level of education (lower, intermediate or tertiary education), employment status (unemployed, working less than 12 hours a week or working more than 12 hours a week), income (divided into four groups, rising from low income (first quartile) to high income (fourth quartile) within the sample), household situation (single household, living with children or other household situations, e.g. married or unmarried couples without children), religiosity (religious or non-religious) and being a care-giver (yes or no) as secondary dimensions. To be able to interpret the tested interaction terms better, all independent variables were categorised.

\section{Analytic strategy}

Intersectionality-informed analysis incorporates both additive and multiplicative approaches (Rouhani, 2014). First, we explored differences on care-giving norms and welfare state orientation between citizens by comparing means in a bivariate analysis (not presented in a table). Second, we are able to explore the effects of 


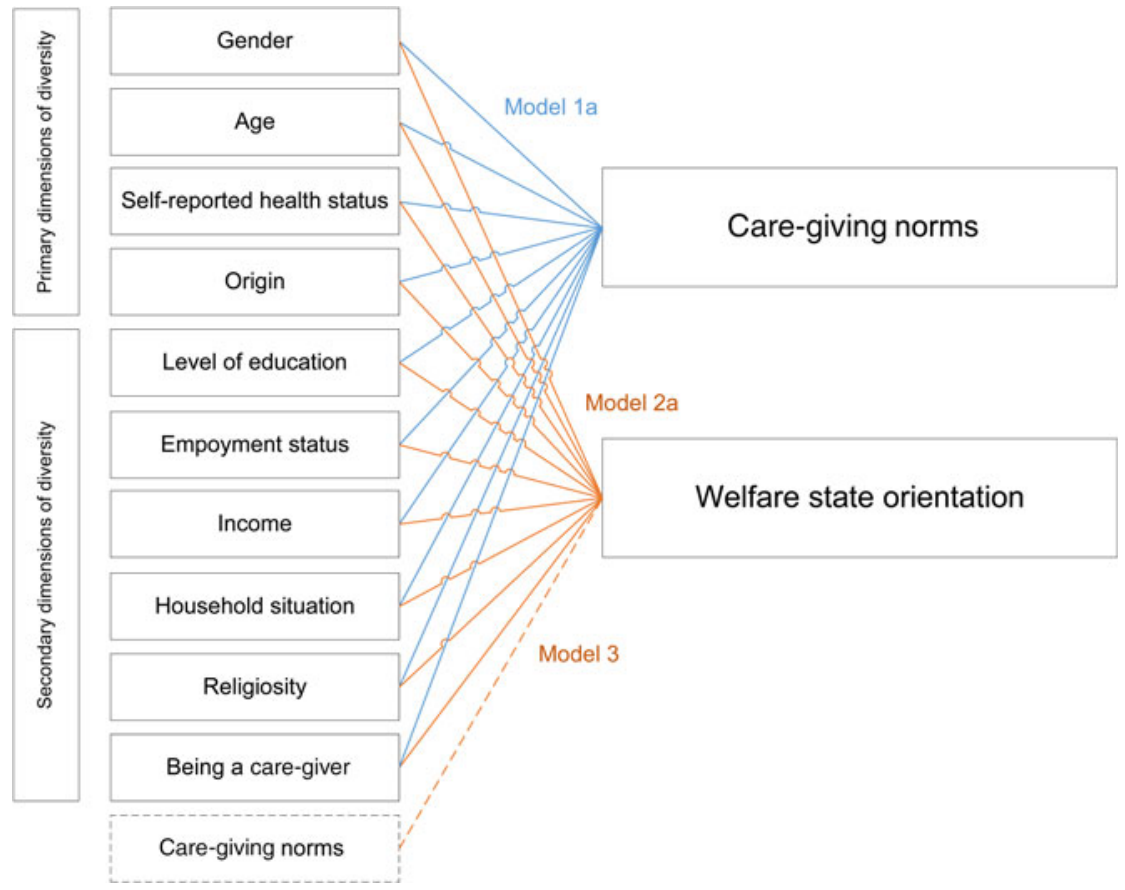

Figure 1. Visualization of regression models 1,2 and 3.

primary and secondary dimensions in relation to care-giving norms and welfare state orientation. Multivariate linear regression analyses were conducted to investigate these effects on care-giving norms (Table 2, Model 1a), and ordered probit regression analyses were conducted to investigate these effects on welfare state orientation (Table 3, Model 2a). By adding the care-giving norm scale to our second regression model (Model 3), we were able to explore the extent to which care-giving norms and welfare state orientation are related (not presented in a table). All models are visualised in Figure 1.

Finally, interaction terms were individually added to Models 1a and 2a to examine the relationship between mutually related factors to care-giving norms and welfare state orientation. Results are presented in Models $1 \mathrm{~b}$ and $2 \mathrm{~b}$ (Tables 2 and 3). Because of the explorative character of our study, the level of significance is $p<0.01$.

\section{Results}

Dutch citizens' care-giving norms are relatively strong, with no scores below 2.78 on a 1-5 scale. Their welfare state orientation shows another pattern with a lowest score of 2.08 on a $1-4$ scale (not presented in a table). Table 1 provides an overview of the respondents who are included in the dataset based on both primary and secondary diversity characteristics. 
Table 1. Respondents' characteristics

N

Primary dimensions of diversity:

Gender:

Male

Female

Age:

16-34

35-64

$65+$

Self-reported health status:

Not limited

Limited

Origin:

Dutch or other Western

Non-Western

Secondary dimensions of diversity:

Level of education:

Lower

Intermediate

Tertiary

Employment status:

Unemployed

Working less than 12 hours

Working more than 12 hours

Income quartile:

$$
1 \text { (low) }
$$

2

3

4 (high)

Household situation:

Single household

Living with children

Other household situation

Religiosity:

Religious

$$
5,293
$$

2,632

2,661

50.3

5,293

1,356

25.6

2,622

49.5

1,315

24.8

5,289

4,243

80.2

1,046

19.8

5,293

4,917

376

5,278

1,463

27.7

2,107

39.9

1,708

23.4

5,293

1,913

36.1

343

3,037

57.4

5,293

790

14.9

1,197

22.6

1,592

30.1

1,714

32.4

5,293

970

18.3

2,494

47.1

1,829

34.6

5,263

2,071 
Table 1. (Continued.)

\begin{tabular}{|ccc}
\hline & $\mathrm{N}$ & $\%$ \\
\hline Non-religious & 3,192 & 60.6 \\
\hline Being a care-giver: & 5,292 & \\
\hline No & 3,950 & 74.6 \\
\hline Yes & 1,342 & 25.4 \\
\hline
\end{tabular}

Table 2. Linear regression models: care-giving norm (Model 1)

\begin{tabular}{|c|c|c|c|c|}
\hline & \multicolumn{2}{|c|}{ Model 1a } & \multicolumn{2}{|c|}{ Model $1 b$} \\
\hline & Coefficient & $p>[t]$ & Coefficient & $p>[t]$ \\
\hline \multicolumn{5}{|l|}{ Primary dimensions of diversity: } \\
\hline \multicolumn{5}{|l|}{ Gender: } \\
\hline Male & 0 (base) & & 0 (base) & \\
\hline Female & -0.223 & $0.000^{\star \star *}$ & -0.364 & $0.000^{\star \star \star}$ \\
\hline \multicolumn{5}{|l|}{ Age: } \\
\hline $16-34$ & 0 (base) & & 0 (base) & \\
\hline $35-64$ & -0.295 & $0.000^{\star * *}$ & -0.295 & $0.000^{* * *}$ \\
\hline $65+$ & -0.292 & $0.000^{\star * *}$ & -0.277 & $0.000^{* \star *}$ \\
\hline \multicolumn{5}{|l|}{ Self-reported health status: } \\
\hline Not limited & 0 (base) & & 0 (base) & \\
\hline Limited & -0.101 & $0.001^{\star *}$ & -0.102 & $0.001^{* *}$ \\
\hline \multicolumn{5}{|l|}{ Origin: } \\
\hline Dutch or other Western & 0 (base) & & 0 (base) & \\
\hline Non-Western & 0.300 & $0.000^{\star \star *}$ & 0.298 & $0.000^{\star \star \star}$ \\
\hline \multicolumn{5}{|l|}{ Secondary dimensions of diversity: } \\
\hline \multicolumn{5}{|l|}{ Level of education: } \\
\hline Lower & 0 (base) & & 0 (base) & \\
\hline Intermediate & -0.096 & $0.001^{\star *}$ & -0.099 & $0.001^{* *}$ \\
\hline Tertiary & -0.021 & 0.520 & -0.022 & 0.490 \\
\hline \multicolumn{5}{|l|}{ Employment status: } \\
\hline Unemployed & 0 (base) & & 0 (base) & \\
\hline Working less than 12 hours & 0.109 & $0.040^{\star}$ & 0.108 & $0.041^{*}$ \\
\hline Working more than 12 hours & 0.016 & 0.639 & 0.020 & 0.563 \\
\hline
\end{tabular}


Table 2. (Continued.)

\begin{tabular}{|c|c|c|c|c|}
\hline & \multicolumn{2}{|c|}{ Model 1a } & \multicolumn{2}{|c|}{ Model $1 b$} \\
\hline & Coefficient & $p>[t]$ & Coefficient & $p>[t]$ \\
\hline \multicolumn{5}{|l|}{ Income quartile: } \\
\hline 1 (low) & 0 (base) & & 0 (base) & \\
\hline 2 & -0.068 & 0.078 & -0.067 & 0.085 \\
\hline 3 & 0.003 & 0.944 & 0.000 & 0.992 \\
\hline 4 (high) & -0.034 & 0.364 & -0.031 & 0.418 \\
\hline \multicolumn{5}{|l|}{ Household situation: } \\
\hline Single household & 0 (base) & & 0 (base) & \\
\hline Living with children & 0.087 & $0.011^{\star}$ & -0.023 & 0.612 \\
\hline Other household situation & -0.031 & 0.367 & -0.094 & 0.054 \\
\hline \multicolumn{5}{|l|}{ Religiosity: } \\
\hline Religious & 0 (base) & & 0 (base) & \\
\hline Non-religious & -0.183 & $0.000^{\star \star \star}$ & -0.187 & $0.000^{\star \star \star}$ \\
\hline \multicolumn{5}{|l|}{ Being a care-giver: } \\
\hline No & 0 (base) & & 0 (base) & \\
\hline Yes & 0.049 & 0.065 & 0.049 & 0.065 \\
\hline \multicolumn{5}{|l|}{ Interactions: } \\
\hline \multicolumn{5}{|l|}{ Gender $\times$ Household situation: } \\
\hline Female $\times$ Single household & & & 0 (base) & \\
\hline Female $\times$ Living with children & & & 0.221 & $0.001^{\star \star}$ \\
\hline $\begin{array}{l}\text { Female } \times \text { Other household } \\
\text { situations }\end{array}$ & & & 0.119 & 0.083 \\
\hline $\mathrm{N}$ & 5,243 & & 5,243 & \\
\hline$R^{2}$ & 0.098 & & 0.101 & \\
\hline
\end{tabular}

Significance levels: ${ }^{\star} p<0.05,{ }^{* *} p<0.01,{ }^{\star \star *} p<0.001$.

\section{Association between diversity characteristics and care attitudes}

We used multivariate linear and ordered probit regression analyses to investigate the individual effects of the independent variables on care attitudes (Tables 2 and 3). Diversity characteristics explain a relatively small proportion of the variance in both the care-giving norm scale $\left(R^{2}=0.098\right)$ and welfare state orientation (pseudo $R^{2}=0.048$ ).

Although all of the primary dimensions of diversity are associated with the caregiving norm scale, only age is associated with people's welfare state orientation. Being female is negatively associated with the care-giving norm scale $(-0.22)$. This also goes for citizens who are aged over $35(-0.29)$, who face health limitations 
Table 3. Ordered probit models: welfare state orientation (Model 2)

\begin{tabular}{|c|c|c|c|c|}
\hline & \multicolumn{2}{|c|}{ Model 2a } & \multicolumn{2}{|c|}{ Model 2b } \\
\hline & Coefficient & $p>[t]$ & Coefficient & $p>[t]$ \\
\hline \multicolumn{5}{|l|}{ Primary dimensions of diversity: } \\
\hline \multicolumn{5}{|l|}{ Gender: } \\
\hline Male & 0 (base) & & 0 (base) & \\
\hline Female & 0.042 & 0.207 & 0.055 & 0.098 \\
\hline \multicolumn{5}{|l|}{ Age: } \\
\hline $16-34$ & 0 (base) & & 0 (base) & \\
\hline $35-64$ & -0.196 & $0.000^{\star \star \star}$ & -0.405 & $0.000^{\star \star \star}$ \\
\hline $65+$ & -0.358 & $0.000^{\star \star \star}$ & -0.697 & $0.000^{\star \star \star}$ \\
\hline \multicolumn{5}{|l|}{ Self-reported health status: } \\
\hline Not limited & 0 (base) & & 0 (base) & \\
\hline Limited & -0.116 & $0.014^{\star}$ & -0.101 & $0.033^{\star}$ \\
\hline \multicolumn{5}{|l|}{ Origin: } \\
\hline Dutch or other Western & 0 (base) & & 0 (base) & \\
\hline Non-Western & 0.082 & 0.224 & 0.074 & 0.275 \\
\hline \multicolumn{5}{|l|}{ Secondary dimensions of diversity: } \\
\hline \multicolumn{5}{|l|}{ Level of education: } \\
\hline Lower & 0 (base) & & 0 (base) & \\
\hline Intermediate & 0.079 & 0.069 & -0.147 & 0.063 \\
\hline Tertiary & 0.295 & $0.000^{\star \star \star}$ & 0.076 & 0.383 \\
\hline \multicolumn{5}{|l|}{ Employment status: } \\
\hline Unemployed & 0 (base) & & 0 (base) & \\
\hline Working less than 12 hours & 0.000 & 0.999 & -0.023 & 0.767 \\
\hline Working more than 12 hours & -0.012 & 0.825 & 0.009 & 0.860 \\
\hline \multicolumn{5}{|l|}{ Income quartile: } \\
\hline 1 (low) & 0 (base) & & 0 (base) & \\
\hline 2 & 0.104 & 0.075 & 0.101 & 0.084 \\
\hline 3 & 0.139 & $0.011^{\star}$ & 0.127 & $0.021^{\star}$ \\
\hline 4 (high) & 0.112 & $0.040^{\star}$ & 0.100 & 0.069 \\
\hline \multicolumn{5}{|l|}{ Household situation: } \\
\hline Single household & 0 (base) & & 0 (base) & \\
\hline Living with children & 0.056 & 0.255 & 0.036 & 0.469 \\
\hline Other household situation & -0.074 & 0.128 & -0.079 & 0.105 \\
\hline
\end{tabular}


Table 3. (Continued.)

\begin{tabular}{|c|c|c|c|c|}
\hline & \multicolumn{2}{|c|}{ Model 2a } & \multicolumn{2}{|c|}{ Model 2b } \\
\hline & Coefficient & $p>[t]$ & Coefficient & $p>[t]$ \\
\hline \multicolumn{5}{|l|}{ Religiosity: } \\
\hline Religious & 0 (base) & & 0 (base) & \\
\hline Non-religious & -0.165 & $0.000^{\star \star \star}$ & -0.163 & $0.000^{\star \star \star}$ \\
\hline \multicolumn{5}{|l|}{ Being a care-giver: } \\
\hline No & 0 (base) & & 0 (base) & \\
\hline Yes & 0.043 & 0.261 & -0.110 & 0.240 \\
\hline \multicolumn{5}{|l|}{ Interactions: } \\
\hline \multicolumn{5}{|l|}{ Age $\times$ Level of education: } \\
\hline 35-64 × Lower & & & 0 (base) & \\
\hline $35-64 \times$ Intermediate & & & 0.252 & $0.014^{\star}$ \\
\hline 35-64 × Tertiary & & & 0.273 & $0.011^{\star}$ \\
\hline $65+\times$ Lower & & & 0 (base) & \\
\hline $65+\times$ Intermediate & & & 0.434 & $0.000^{\star \star \star}$ \\
\hline $65+\times$ Tertiary & & & 0.302 & $0.017^{\star}$ \\
\hline \multicolumn{5}{|l|}{ Age $\times$ Being a care-giver: } \\
\hline $35-64 \times$ No & & & 0 (base) & \\
\hline $35-64 \times$ Yes & & & 0.108 & 0.307 \\
\hline $65+\times$ No & & & 0 (base) & \\
\hline $65+\times$ Yes & & & 0.378 & $0.002^{\star \star}$ \\
\hline $\mathrm{N}$ & 5,197 & & 5,197 & \\
\hline Nagelkerke pseudo $R^{2}$ & 0.048 & & 0.053 & \\
\hline
\end{tabular}

Significance levels: ${ }^{*} p<0.05,{ }^{* \star} p<0.01,{ }^{* \star *} p<0.001$.

$(-0.10)$ and who are of Dutch or other Western origin. Looking at welfare state orientation, it seems that the older people are, the smaller the chance they think care for people in need is mainly the family's responsibility. Differences in welfare state orientation based on gender, health and origin were not significant in the multivariate analyses.

Looking at secondary dimensions of diversity, level of education and religiosity turn out to be significantly associated with care attitudes: an intermediate level of education is negatively associated with the care-giving norm scale $(-0.10)$, as is being non-religious $(-0.18)$, indicating a higher chance of having weaker caregiving norms. In regards to welfare state orientation, the same pattern was found for religiosity, but for level of education the results are different: people with tertiary levels of education have a higher chance of assigning more responsibility to the 
family instead of the government. Other differences with secondary dimensions of diversity were not significant in the multivariate analyses.

To assess whether citizens with strong care-giving norms assign less responsibility for care to the state, we added the care-giving norm scale to our second model. The care-giving norm scale was positively associated with welfare state orientation (0.63, $p \leqslant 0.001$, not presented in a table), corroborating the assumption that citizens with strong care-giving norms attribute less responsibility for care to the state (Daatland and Herlofson, 2003; Verbakel, 2014). The care-giving norm scale increased the explanatory power of the model (pseudo $R^{2}=0.096$, not presented in a table).

\section{Interactions}

We used multiplicativity to look into the conditional effects of intersecting diversity characteristics. Results are presented in Models $1 b$ and $2 b$ (Tables 2 and 3). In the first model, an interaction was found between gender and household situation. Women living with children have stronger care-giving norms than those in single or other household situations. This difference does not apply to men (Figure 2). After adding this interaction, the associations found in the initial model (Table 2) remain significant.

In the second model, interactions were found between age and level of education (Figure 3) and age and being a care-giver (Figure 4). People with a lower level of education assign relatively more responsibility to the government than the family, and once people are older the proportion of people considering the government responsible increases. This effect is less visible among groups with intermediate and tertiary education. Citizens aged 65 or older who are providing informal

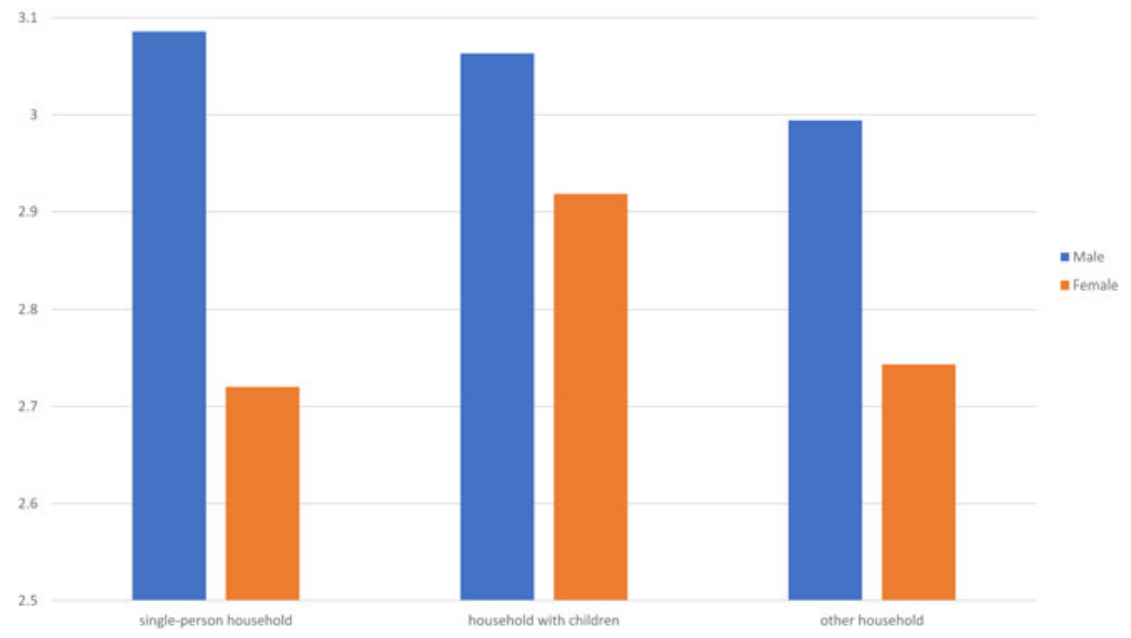

Figure 2. Visualization interaction care-giving norms - gender and household situation. 


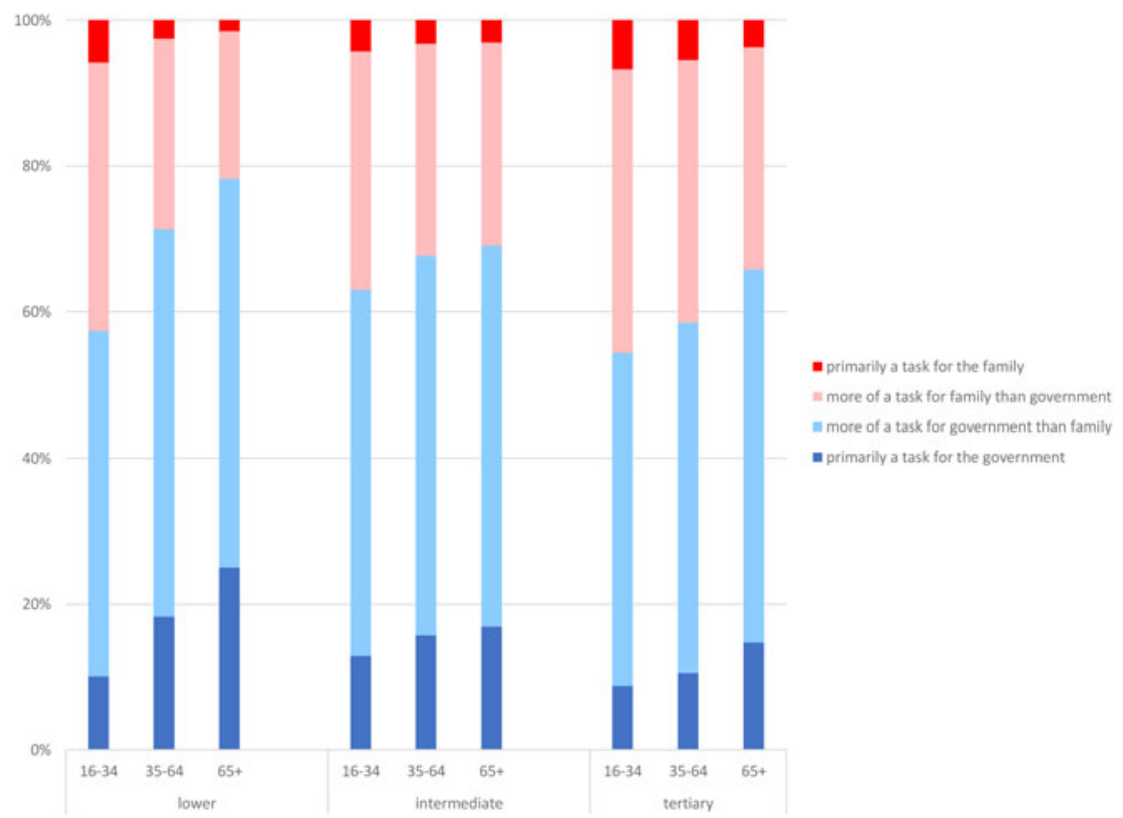

Figure 3. Visualization interaction welfare state orientation - age and level of education.

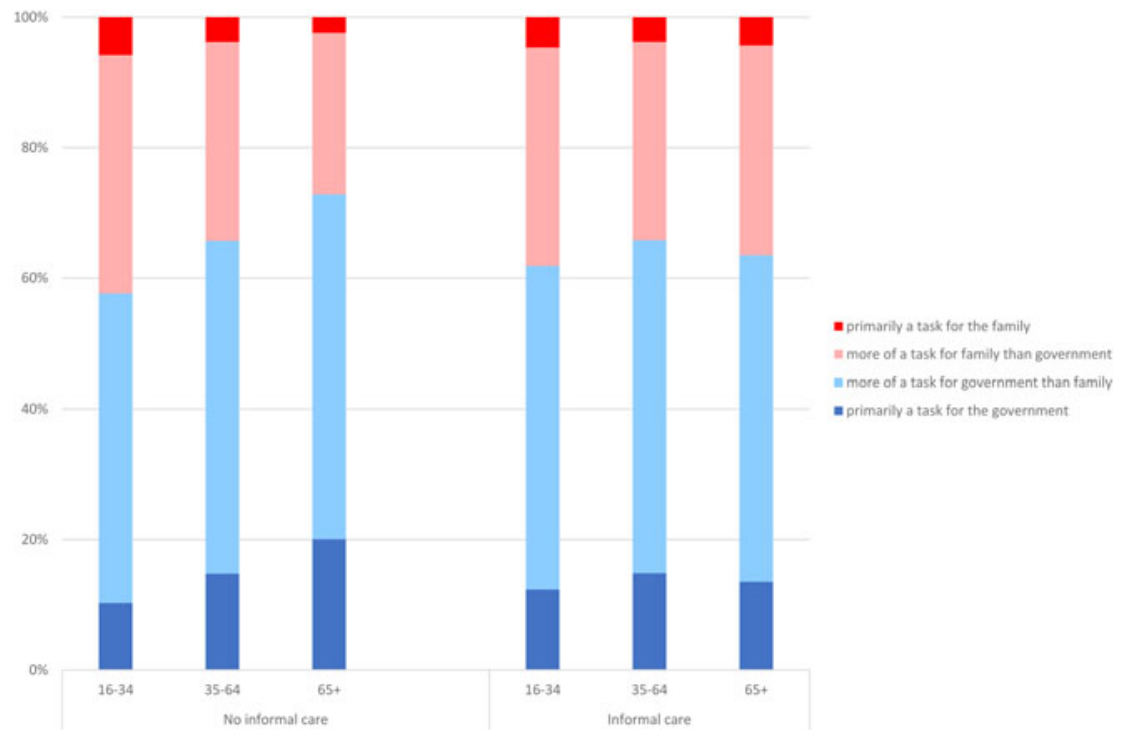

Figure 4. Visualization interaction welfare state orientation - age and being a caregiver.

care assign more care responsibility to the family instead of the welfare state, compared to people who do not provide informal care. After adding these interactions to the initial model (Table 3), the main effect of level of education is no longer significant. 


\section{Discussion}

Our study sheds light on the distinct pathways of care attitudes of citizens. Using a large national representative sample of more than 5,000 respondents, it was shown that care attitudes are mixed, because care-giving norms of Dutch citizens are relatively strong. People also consider care for persons with disabilities and older people a state responsibility though.

Hypothesis 1 on care-giving norms was supported by our results. We observed that men's care-giving norms are stronger than women's, and that citizens in good health and people of non-Western origin have strong care-giving norms. The expected differences in welfare state orientation based on gender (van den Broek et al., 2015; Hoefman et al., 2017) were not found. Also, contrary to our expectation, younger people assign relatively more responsibility to the family and have stronger care-giving norms as well. Based on our results, we cannot properly explain why these results for younger people differ from our expectations. Younger people may be more accustomed to the decline of publicly funded services and the withdrawal of the welfare state than others. However, more in-depth research would be needed to be able to interpret these results better. Our multivariate analyses showed no significant associations between health problems, origin and welfare state orientation.

The expected relation of secondary diversity characteristics and care attitudes (Hypothesis 2) was partly supported by our results. Higher-educated people do attribute relatively more care responsibility to the family than to the government, and care attitudes of those who are religious are stronger than of those who are not. No significant differences in care attitudes were found based on employment status, income, household situation and being a care-giver or not. These results are somewhat surprising, as in the intersectional approach, associations between citizens' social identities and situational circumstances are assumed (Hancock, 2007; Hankivsky and Cormier, 2009). The reason might be that citizens' care attitudes were investigated within the Dutch context of generous welfare state arrangements (van den Broek et al., 2019) and individualistic cultural norms (Dykstra and Fokkema, 2012), causing favourable circumstances for citizens (e.g. possibilities to work in part-time jobs, high-quality social services). Future research would therefore need other dimensions of diversity to be able to investigate the influence of situational circumstances on care attitudes of people. Specific care-giving research suggests that contextual factors such as cultural, economic and health system characteristics are significant (Fletcher et al., 2012). More in general, dimensions such as socio-cultural environment, political differences or geography are suggested to be included (Hankivsky and Cormier, 2009; Rouhani, 2014). Unfortunately, our dataset did not include such determinants.

To explore the extent to which care-giving norms and welfare state orientation are related, we added the care-giving norm into the analysis of welfare state orientation. This increased the explanatory power of the welfare state orientation model. This indicates that there is an association between both aspects of care attitudes. We assume that the increased explanatory power of the model means that diversity is probably foremost associated with care-giving norms, and that care-giving norms are subsequently associated with citizens' welfare state orientation. This is in line 
with the literature assuming that subjective norms influence behavioural intentions, and that the reverse does not apply (Daatland and Herlofson, 2003). This lack of clarity calls for more research regarding whether and how care attitudes of citizens evolve from care-giving norms into welfare state orientation and how this interacts with actual care-giving behaviour.

We found evidence for an interaction between primary and secondary dimensions of diversity. Hypothesis 3 is thus partly supported by our observations. People with lower levels of education assign relatively more responsibility to the government than to the family, but once people are older the proportion of people considering the government responsible increases. This may be related to the decline of filial norms as people get older (Gans and Silverstein, 2006). Women who live with children have stronger care-giving norms, whilst this difference is absent for men. Possibly, this is caused by the persistence of gender role differentiation in modern families (Silverstein et al., 2006; Dykstra and Fokkema, 2012). Older care-givers assign relatively more responsibility to the family than to the government compared to non-care-givers. This difference is absent for younger people. Possibly this is because the likelihood of providing care increases with age or because older care-givers are more altruistic (Peng and Anstey, 2019). Another explanation might be that older care-givers mainly help their partner and younger care-givers help their parents (de Klerk et al., 2017). The intersectional approach provided insights into the mutual reinforcement of these characteristics in relation to care attitudes. Without this approach, these groups with specific care attitudes would be overseen while in these groups inequality may arise. For example, the persistence of gender role differentiation in modern families may have consequences for (the absence of) fair opportunities for both men and women who provide informal care whilst having children, as suggested for example by Browning (2021).

This study also has limitations. First, the intersectional approach could have been used even more in detail in our analysis. We investigated interactions between primary and secondary dimensions of diversity, but not between primary or between secondary dimensions. Future research using this type of analysis could expose even more accurate insights about differences in care attitudes. This may expose specific groups who are at risk of unequal opportunities based on their care attitudes in combination with relevant determinants that influence actual care-giving behaviour. For example, this could provide specific information about young women or men of non-Western origin. Furthermore, using qualitative methods in follow-up research could provide complementary insights into the way power shapes dimensions of diversity and into the dynamic interaction between primary and secondary diversity dimensions (Hancock, 2007; Grace, 2014; Hankivsky, 2014). Second, the low explanatory strength of our models may be caused by our measuring methodology. For example, our care-giving norm scale $\left(R^{2}=0.098\right)$ could be further improved by integrating items from the scale developed by Lee et al. (1998) to measure filial norms. This may enhance the explanatory strength of the model.

\section{Conclusions}

Based on our intersectional approach to investigate care attitudes, we conclude that primary dimensions of diversity are more related to care attitudes than secondary 
dimensions: gender, age, self-reported health and origin are significantly related to care-giving norms. Furthermore, age is significantly related to welfare state orientation, whereas only level of education and religiosity are significantly related to both care-giving norms and welfare state orientation. Combined with the finding that several dimensions are related, such as age and care-giving are, we conclude that intersectionality is a valuable approach to explore diversity in relation to care attitudes. As it turns out, care attitudes are in some cases indeed shaped by multidimensional processes (Hunting, 2014). Insights into these differences in care attitudes offer professionals the opportunity to align better with citizens' attitudes. Talking about care attitudes could improve clarity about provided care, which is important to improve collaboration between informal and formal care-givers (Wittenberg et al., 2018). Institutions that provide training in the areas of social work and (allied) health can use our insights to give upcoming professionals a better understanding of differences between groups of citizens regarding care attitudes. Expertise and attitudes of social workers and (allied) health professionals can also be expanded using our insights.

One of the possible consequences of more focus on informal care policy is that the corroborating care attitudes become more complex, as people and sub-groups vary to a large extent in their care-giving norms and welfare state orientation. The differences shown in our study reflect the fact that populations are diverse (Vertovec, 2007) and that one cannot make generalisations of all citizens about their care attitudes. In the relatively new Dutch long-term care model, more emphasis is placed on providing informal care (Broese van Groenou and de Boer, 2016; van den Broek et al., 2019). Combined with the fact that there will be a strong decrease in the number of potential care-givers in the future (Herrmann et al., 2010), policy makers need to pay attention to groups of citizens who have less-strong care-giving norms. For those, it might be less obvious to actually provide informal care when needed (Peng and Anstey, 2019). On the other hand, it is important to make sure that people with strong care attitudes will not become overburdened because of their informal care tasks. Policy makers should realise that although many people are willing to help, they do expect some kind of commitment and help from the government as well.

Acknowledgements. We would like to thank Jurjen Iedema, methodologist at The Netherlands Institute for Social Research, for his support during this research project.

Author contributions. All authors contributed to the conception and design, interpretation of the data and drafting of the article, and approved the version to be published. Furthermore, the first, second and third authors conducted data analysis.

Financial support. This work was supported by the Dutch Research Council (NWO) (project number 023.011.009, Doctoral Grand for Teachers). NWO played no role in the design, execution, analysis and interpretation of data, or the writing of the study.

Conflict of interest. The authors declare no conflicts of interest.

Ethical standards. Ethical approval was not required. Participants received written study information, and participation was elective. Data collection was in strict accordance with the national standard. At no time did the datasets contain direct identifiers. 


\section{References}

Akkan B (2020) An egalitarian politics of care: young female carers and the intersectional inequalities of gender, class and age. Feminist Theory 21, 47-64.

Bauer GR (2014) Incorporating intersectionality theory into population health research methodology: challenges and the potential to advance health equity. Social Sciences \& Medicine 110, 10-17.

Beneken genaamd Kolmer D, Tellings A and Gelissen J (2008) Partnership in health care: views of family caregivers on sharing care responsibility with government, clients and health insurers. Medicine and Law 27, 705-730.

Blieszner R and Bedford VH (eds) (2012) Handbook of Families and Aging, 2nd Edn. Santa Barbara, CA: Praeger.

Broese van Groenou MI and de Boer A (2016) Providing informal care in a changing society. European Journal of Ageing 13, 271-279.

Browning SDA (2021) The Mental Health and Well-being of Informal Caregivers in Europe: Regime Type, Intersectionality, and the Stress Process (Doctoral dissertation). University of Victoria, Victoria, Canada. Available at http://dspace.library.uvic.ca/bitstream/handle/1828/12877/Browning_Sean_PhD_2021.pdf? sequence $=3$ \& is Allowed $=\mathrm{y}$.

Chappell NL, Dujela C and Smith A (2015) Caregiver well-being: intersections of relationship and gender. Research on Aging 37, 623-645.

Choo HY and Ferree MM (2010) Practicing intersectionality in sociological research: a critical analysis of inclusions, interactions, and institutions in the study of inequalities. Sociological Theory 28, 129-149.

Coumans M and Knops J (2017) Onderzoeksverantwoording Culturele veranderingen en SCP Leefsituatie Index 2016. Statistics Netherlands. Available at https://www.scp.nl/Onderzoek/Bronnen/Beknopte onderzoeksbeschrijvingen/Culturele_veranderingen_in_Nederland_CV/CV_documentatie/documentatie_ CV2016.

Coumans M and Knops J (2019) Onderzoeksverantwoording Culturele veranderingen en SCP Leefsituatie Index 2017-2018. Statistics Netherlands. Available at https://www.scp.nl/Onderzoek/Bronnen/Beknopte_ onderzoeksbeschrijvingen/Culturele_veranderingen_in_Nederland_CV/CV_documentatie/Documentatie_ CV_2018.

Daatland SO and Herlofson K (2003) 'Lost solidarity' or 'changed solidarity': a comparative European view of normative family solidarity. Ageing \& Society 23, 537-560.

Davis K (2008) Intersectionality as buzzword. A sociology of science perspective on what makes a feminist theory successful. Feminist Theory 9, 67-85.

de Klerk M, de Boer A, Plaisier I and Schyns P (2017) Voor elkaar? Stand van de informele hulp 2016. The Hague: Sociaal en Cultureel Planbureau.

Dilworth-Anderson P, Moon H and Aranda MP (2020) Dementia caregiving research: expanding and reframing the lens of diversity, inclusivity, and intersectionality. The Gerontologist 60, 797-805.

Dykstra PA and Fokkema T (2009) Persoonlijke zorgnormen: bereidheid te geven én te ontvangen. In de Boer A (ed.), Toekomstverkenning informele zorg. The Hague: The Netherlands Institute for Social Research, pp. 122-142.

Dykstra PA and Fokkema T (2012) Norms of filial obligation in the Netherlands. Population 67, 97-122.

Fletcher BS, Miaskowski C, Given B and Schumacher K (2012) The cancer family caregiving experience: an updated and expanded conceptual model. European Journal of Oncology Nursing 16, 387-398.

Gans D and Silverstein M (2006) Norms of filial responsibility for aging parents across time and generations. Journal of Marriage and Family 68, 961-976.

Giesbrecht M, Crooks VA, Williams A and Hankivsky O (2012) Critically examining diversity in end-of-life family caregiving: implications for equitable caregiver support and Canada's Compassionate Care Benefit. International Journal for Equity in Health 11, 1-13.

Grace D (2014) Intersectionality-informed Mixed Methods Research: A Primer. The Institute for Intersectionality Research \& Policy, SFU. Available at https:/ktpathways.ca/system/files/resources/ 2019-09/Intersectionality-informed_Mixed_Method.pdf.

Haberkern K and Szydlik M (2010) State care provision, societal opinion and children's care of older parents in 11 European countries. Ageing \& Society 30, 299-323.

Hancock A-M (2007) Intersectionality as a normative and empirical paradigm. Politics \& Gender 3, 248-254. 
Hankivsky O (2014) Intersectionality 101. The Institute for Intersectionality Research \& Policy, SFU. Available at https://www.researchgate.net/publication/279293665_Intersectionality_101.

Hankivsky $\mathbf{O}$ and Cormier R (2009) Intersectionality: Moving Women's Health Research and Policy Forward. Vancouver, Canada: Women's Health Research Network.

Herrmann FR, Michel J-P and Robine J-M (2010) Worldwide decline in the oldest old support ratio. European Geriatric Medicine 1, 3-8.

Hoefman RJ, Meulenkamp TM and de Jong JD (2017) Who is responsible for providing care? Investigating the role of care tasks and past experiences in a cross-sectional survey in the Netherlands. BMC Health Services Research 17, 1-12.

Hunting G (2014) Intersectionality-informed Qualitative Research: A Primer. The Institute for Intersectionality Research \& Policy, SFU. Available at https://www.ifsee.ulaval.ca/sites/ifsee.ulaval.ca/ files/b95277db179219c5ee8080a99b0b91276941.pdf.

Kenny P, King MT and Hall J (2014) The physical functioning and mental health of informal carers: evidence of care-giving impacts from an Australian population-based cohort. Health and Social Care in the Community 22, 646-659.

Lee GR, Peek CW and Coward RT (1998) Race differences in filial responsibility expectations among older parents. Journal of Marriage and the Family 60, 404-412.

Loden M and Rosener JB (1990) Workforce America! Managing Employee Diversity as a Vital Resource. New York, NY: McGraw-Hill Education.

Mair CA, Quiñones AR and Pasha MA (2015) Care preferences among middle-aged and older adults with chronic disease in Europe: individual health care needs and national health care infrastructure. The Gerontologist 56, 687-701.

McCall L (2005) The complexity of intersectionality. Signs 30, 1771-1800.

Peng R and Anstey KJ (2019) Longitudinal study of factors associated with informal care provision: evidence from older Australians. Australasian Journal on Ageing 38, 98-106.

Rouhani S (2014) Intersectionality-informed Quantitative Research: A Primer. The Institute for Intersectionality Research \& Policy, SFU. Available at https:/www.ifsee.ulaval.ca/sites/ifsee.ulaval.ca/ files/9eba2da23ab70bfadd9ca2e076af4a3a62cc.pdf.

Santoro MS, Van Liew C, Holloway B, McKinnon S, Little T and Cronan TA (2016) Honor thy parents: an ethnic multigroup analysis of filial responsibility, health perceptions, and caregiving decisions. Research on Aging 38, 665-688.

Silverstein M, Parrott TM and Bengtson VL (1995) Factors that predispose middle-aged sons and daughters to provide social support to older parents. Journal of Marriage and the Family 57, 465-475.

Silverstein M, Gans D and Yang FM (2006) Intergenerational support to aging parents. The role of norms and needs. Journal of Family Issues 27, 1068-1084.

Triantafillou J, Naiditch M, Repkova K, Stiehr K, Carretero S, Emilsson T, Di Santo P, Bednarik R, Brichtova L, Ceruzzi F, Cordero L, Mastroyiannakis T, Ferrando M, Mingot L, Ritter J and Vlantoni D (2010) Informal Care in the Long-term Care System (European Overview Paper). Athens and Vienna: Interlinks. Available at https://www.euro.centre.org/downloads/detail/768.

van den Broek T, Dykstra PA and van der Veen RJ (2015) Care ideals in the Netherlands: shifts between 2002 and 2011. Canadian Journal on Aging/La Revue canadienne du vieillissement 34, 268-281.

van den Broek T, Dykstra PA and van der Veen RJ (2019) Adult children stepping in? Long-term care reforms and trends in children's care provision of household support to impaired parents in the Netherlands. Ageing \& Society 39, 112-137.

Verbakel E (2014) Toenemende publieke steun voor meer eigen verantwoordelijkheid in de zorg? Bestuurswetenschappen 68, 5-23.

Verbakel E (2017a) How to understand informal caregiving patterns in Europe? The role of formal longterm care provisions and family care norms. Scandinavian Journal of Public Health 46, 1-12.

Verbakel E (2017b) Informal care in Europe: findings from the European Social Survey (2014) special module on the social determinants of health. European Journal of Public Health 27, 90-95.

Verbeek-Oudijk D, Woittiez I, Eggink E and Putman L (2014) Who Cares in Europe? A Comparison of Long-term Care for the Over-50s in Sixteen European Countries. The Hague: The Netherlands Institute for Social Research.

Vertovec S (2007) Super-diversity and its implications. Ethnic and Racial Studies 30, 1024-1054. 
Williams A, Sethi B, Duggleby W, Ploeg J, Markle-Reid M, Peacock S and Ghosh S (2016) A Canadian qualitative study exploring the diversity of the experience of family caregivers of older adults with multiple chronic conditions using a social location perspective. International Journal for Equity in Health 15, 40.

Winker G and Degele N (2011) Intersectionality as multi-level analysis: dealing with social inequality. European Journal of Women's Studies 18, 51-66.

Wittenberg Y, Kwekkeboom R, Staaks J, Verhoeff A and de Boer A (2018) Informal caregivers' views on the division of responsibilities between themselves and professionals: a scoping review. Health and Social Care in the Community 26, e460-e473.

Cite this article: Wittenberg Y, de Boer AH, de Klerk MMY, Verhoeff AP, Kwekkeboom R (2023). How to understand diversity in citizens' care attitudes: an exploratory study in the Netherlands. Ageing \& Society 43, 1164-1183. https://doi.org/10.1017/S0144686X21001082 